\section{The craftsmen of Kyoto}

\author{
Pip Dickens
}

The decline of the katagami stencil and its symbolic use in this book for the skill of making things well can usefully be set within contemporary and economic contexts, in a review of the status of kimono making in Japan today. According to Danielle Demetriou: 'The kimono industry, which produces one of the most enduring cultural symbols of Japan, is in crisis'. ${ }^{1}$

My research in Kyoto (April 2011) included meeting a young kimono designer, Makoto Mori, who writes about the history and current developments in kimono making in the next chapter. Mori and other young Kyoto designers are embracing technology Illustrator and Photoshop being primary tools. To appreciate this move away from hand skills, it is important to understand how the traditional kimono is made and, ultimately, the cost to the customer (and the maker). As Demetriou states: 'Most craftsmen today are over 80 and within the next 10 years many

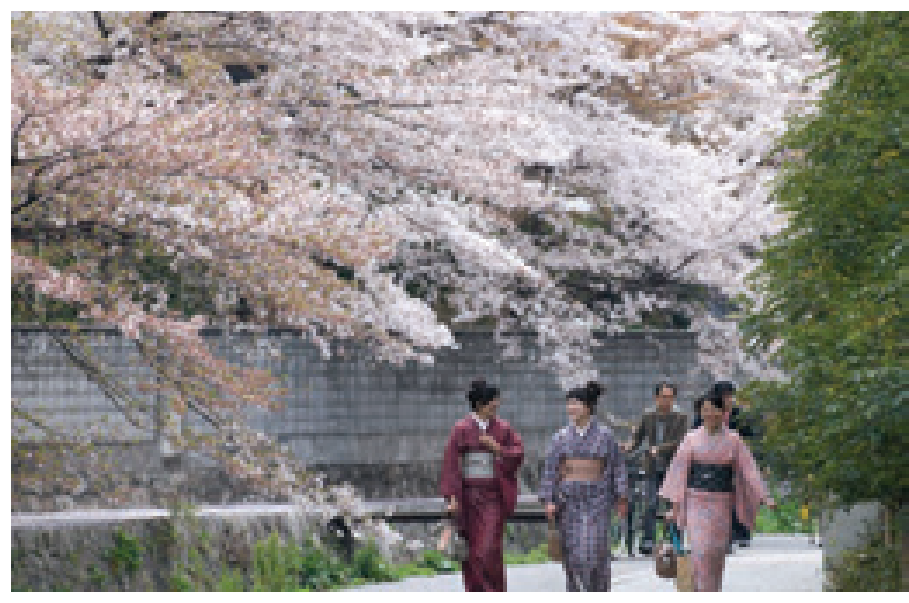

Figure 7.2 Japanese women enjoying the cherry blossom along the Shirakawa river in Okazaki. @ ( Jeffrey Friedl will pass away. We are in real danger of losing thousands of years of kimono-making techniques.' $^{2}$

To commission, or purchase, a kimono utilising traditional hand skills one should expect to pay, at a minimum, about $¥ 1$ million (approximately $£ 8,400$ ). Some well-heeled Tokyo businessmen will spend double that on kimonos for their wives. Few people have that kind of money to spend on what is no longer considered regular attire - even in Kyoto, which is Japan's capital of culture and tradition.

My research trip fell during the popular cherry blossom season when hanami (blossom appreciation) activities abound - stalls and vendors line the processional walks to favoured beauty spots containing the revered cherry trees. People reserve places for picnics under these trees, camping out well into the night and feasting on the delicacies provided by the street vendors. This is a time when Kyoto is usually very busy with overseas and Japanese visitors, and it is common to see kimonos being worn during the processional walks and celebrations. Since my visit followed the recent devastating earthquake and tsunami, there were few overseas tourists in Kyoto, but Japanese tourists still flocked to see the cherry blossom. The most impressive wearers of kimonos were mature ladies, who obviously revered both the custom of hanami and the opportunity to wear their high-quality kimonos, which they did with great grace and pride. Conversely, there were younger girls wearing what were obviously cheaper, printed kimonos - eager to be caught on camera by, they hoped, equally eager tourists. 
For young or old, wearing a kimono is something special but also something of a spectacle these days (see Figure 7.3). The kimono is not a utility garment and, on a hot April day, wearing one with good grace is a skill in itself. Demetriou writes:

As kimonos have gone out of fashion, the number of companies making them in Tokyo has shrunk - dwindling from 217 to 24 over the past 30 years. Even in Kyoto, the historic centre for traditional Japanese culture, there are now just 64 kimono makers left. ${ }^{3}$

The art and craft of kimono making precedes the Western concept of haute couture (developed in mid-nineteenth century Paris by British designer Charles Worth), where many skilled people combine to produce specific elements of a bespoke garment. As outlined in Chapter 2, it takes many skilled artisans to make a katagami stencil and this, in turn, is but one element contributing to a kimono's fabrication and design. There are a very significant number of different, highly skilled, procedures and techniques employed at each stage. Dyeing, painting, embroidery, and silk making are fast disappearing in Japan. No computer can completely replace these skills and there is real danger of exchanging original skill for simulacrum effect - for example, a computer-generated pattern that replicates a shibori technique. However, computers are able to capture, record and archive a vast library of techniques as reference material.

The kimono industry is suffering a Janus-faced conundrum of transition versus tradition. It shares parallels with Western Art's recent history of reproduction in the mechanical age in that a computer-generated image of a painting is not an artwork - it is an image of an artwork. The painting becomes something different once it has been reproduced - colours change, spatial depth is lost, materiality is lost. Reproduction is only as a good as the camera that has photographed the original work. As we move further and further away from the original, we move further away from the point of art itself - the object, how it is made and what it is made of.

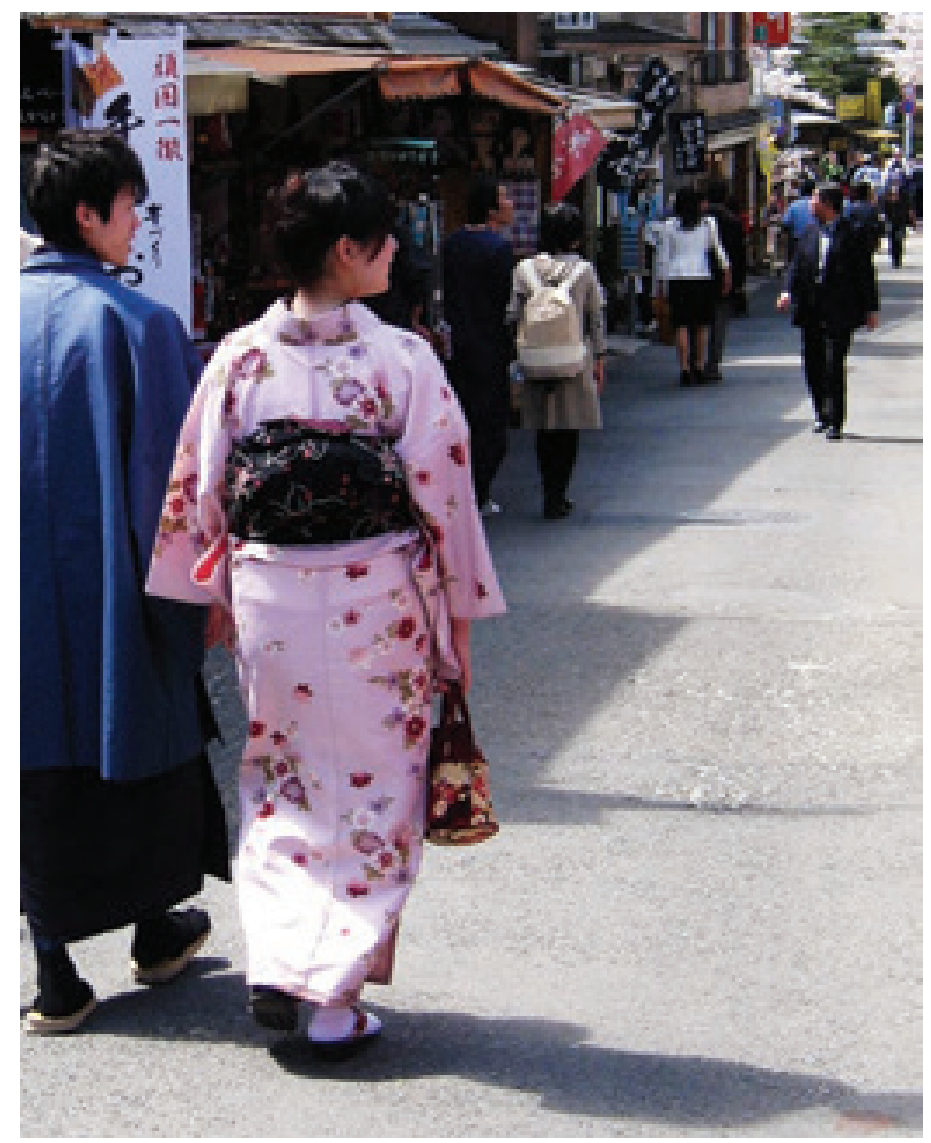

Figure 7.3 A young couple in traditional dress head towards the hanami cherry viewing festivities in Kyoto, 2010.

(C) Pip Dickens

The reason for this transition in the kimono industry is due in part to the decline of skilled artisans and a younger generation who cannot justify, economically, the time-investment in apprenticeships to learn these skills. The pressure on the industry to build a viable business practice has required it to explore and exploit other technologies. The alternative of hiring in traditional skill sets and expertise from a diverse yet ever-dwindling pool of resources is becoming less and less practicable.

Writing in 2007, Anthony Faiola from the Washington Post described the last generation of skilled artisans in the Nishijin district of Kyoto:

Yasujiro Yamaguchi worked the humming loom in his private workshop. Patiently lacing golden threads through a warp of auburn silk, he fashioned a bolt of kimono 
fabric blooming with an autumn garden in shades of tea green, ginger and plum. But Yamaguchi, like Japan's signature kimono, is slipping into winter. At 102, he is among the last master weavers of Nishijin, the country's most celebrated kimono district, and his pace has slowed. He rubbed the morning chill from his knuckles, fitted his hunched shoulders deeper inside his indigo jacket and resolutely pushed on. ${ }^{4}$

At the time of the interview with Faiola, Yamaguchi was one of only three masters left who could actually create a kimono from scratch. All were over 70 years old and none had apprentices. Yamaguchi stated: 'It is a sign of the times ... I am not sure who will carry on this tradition for future generations. I no longer have the time or energy to teach someone now. Even if I did, where would they work?'5 Faiola reports that sales of Nishijin kimonos and related products fell from US $\$ 2.7$ billion in 1990 to a record low of US $\$ 477$ million in 2006; production of kimonos in this region (which is known for its quality) dropped from 291,000 to just 87,382 garments.

In 2011, through an introduction from Professor Yuzo Murayama, Director of Innovative Globalization of Kyoto's Heritage Industries at Doshisha Business School in Kyoto, I met three designers who are bravely negotiating the chasm between tradition and transition, utilising kimonos (and kimono techniques) in different ways. For Murayama, these three designers exemplify new possibilities in Japan's cultural business sector:

Although Japanese culture is enjoying a worldwide boom, particularly in 'anime' and 'manga', Kyoto's heritage industries are mired in a slump. Some are even in danger of disappearing completely. One reason for this lies in the fact that heritage industries have lost their horizons for lateral development, particularly their motivation for entering the global marketplace. The only means of overcoming these difficulties are those of novel innovations and of going global. The concept that holds the key to its success is that of 'cultural businesses'.
The Kakushin Juku [a class being offered by Doshisha Business School] is leading the way along the path from heritage industries to cultural businesses. ${ }^{6}$

With the aid of a computer, the designers' artistic vision, or style, remains independent, which, in turn, means greater creative freedom, lower overheads and time-saving approaches. This is crucial, since few people are able to invest $¥ 1$ million on a kimono. This is the reality. The designers' approach, therefore, has to be one that preserves what they perceive to be valued traditional elements and skills, and re-present, or incorporate them, into products for a contemporary market be it through bespoke or multiple quality products at competitive cost.

The designers featured here are, literally, the children of kimono designers and so represent the departure point between traditional collaborative techniques and independence through contemporary technology. From a personal and professional perspective, the act of refocusing to meet the modern, more cut-throat economy leaves them caught between a rock and a hard place, since they are reminded, almost daily, of the magnitude of their cultural history (through their parents, relatives and community). ${ }^{7}$ A great ocean of possibility awaits them through new innovation, but the problem for them is how, and what, to carry with them into the cultural industry of the future. They are only too aware that as they progress there is always the danger of leaving behind, perhaps forever, knowledge and skills that cannot be regained. These are three designers who are making a very bold step forward.

\section{Yunosuke Kawabe: Japan Style System}

Yunosuke Kawabe launched his company, Japan Style System, in the late 1990s. ${ }^{8}$ His professional development is significant in that he was the oldest son in the family's kimono workshop. His father, Zenji, is a traditional craftsman, and recognised as an Exceptional Artisan by the Governor of Kyoto Prefecture. Zenji's kimonos evidence huge complexity of design, intricacy and colour, with a 


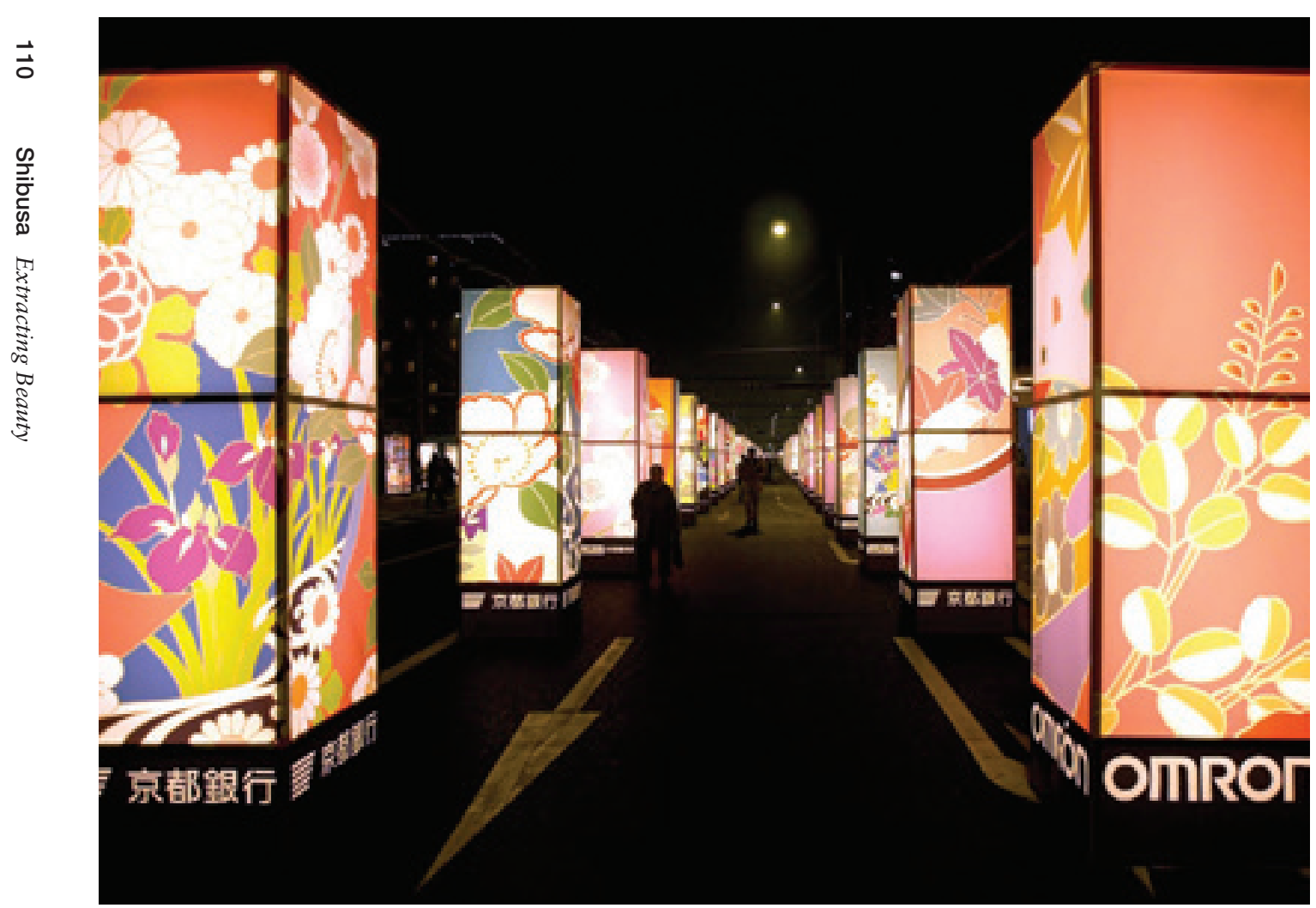

Figure 7.4 Kawabe's dramatic giant yuzen lanterns in Kyoto city, celebrating the millennium. (C) Yunosuke Kawabe

multiplicity of techniques applied to a single garment (see Figure 7.1).

Yunosuke studied graphic design at art school and, during this period, was captivated by the posters publicising the 1976 Montreal Olympics. He decided not to join his father's kimono and yuzen workshop after graduating, and instead entered the world of advertising. However, in 1988 he returned home to study with his father, thus beginning a fusion between the old and the new in yuzen design. Ten years later he began using computer technology to produce yuzen designs, and one of his first large projects was designing 250 large-scale freestanding silk lanterns for the Kyoto Lantern Festival to celebrate the new millennium (see Figure 7.4).

Yuzen is a method of hand painting, or printing, colour and pattern on to kimono fabric, usually silk. Tegaki-yuzen is hand painted, while kata-yuzen is printed with the katagami stencil. Yuzen dyeing techniques include painting directly on to silk and the use of paste as the resist for maintaining clear areas (as outlined in Chapter 2). After the colours are fixed, the paste is removed by gently washing the cloth in running water. Fine lines between sections of design are produced by using special piping cones (like icing bags), separating one area of colour from another this is called tsutsugaki. Many other procedures involve similar processes, using a range of different shaped brushes or mediums. It is a very complex and skilled area, so each process, however subtle, is given a specific name. Yuzen style varies from region to region - for example Kyo-yuzen (Kyoto), Tokamachiyuzen (Tokamachi, Niigata). In Kyoto it has been traditional for yuzen artists to gently wash their fabric in the Kamo river every August. $^{9}$

Yunosuke Kawabe has, through the pushme-pull-you experience of working in new industries and returning to old traditions, integrated what he feels is the best of both worlds: producing new products using the 
traditions of yuzen, combined with computeraided design. His products include swimsuits, interiors, theatrical backdrops, chairs, cushions, clocks, and even cars (see Figure 7.5).

The Kyoto car project, explains Professor Murayama, was:

sponsored by Venture Business Laboratory at Kyoto University and sought to mix Kyoto's high technology with Kyoto's traditional Yuzen designs. The result was eight conceptual models of electric cars (one-tenth of the actual sized-cars) which were presented at the G8 Foreign Ministers' Meeting held in Kyoto in 2008. Tomotaka Takahashi, a famous robot creator from Kyoto, designed the car bodies and Yunosuke Kawabe made surface designs. ${ }^{10}$

This may seem little more than implanting historically derivative yuzen designs on to contemporary products, but Yunosuke Kawabe goes to great lengths to explain how colour combinations in yuzen design are critical, together with his innate skills of draughtsmanship. As an inheritor of the techniques of Kyoto traditional crafts through the training from his father - he is able to carry these important heritage skills forward. His home doubles as his studio: the walls are decorated with his father's extravagant kimonos, sofas are festooned with his contemporary yuzen silk cushion covers and computer equipment sits side by side with paint pots and brushes.

Kawabe also designed the official swimwear of the Japanese synchronised swimming team for the 2004 Athens Olympics (see Figure 7.6). His swimsuits were based on $k a b u k i^{11}$ and were launched by Mizuno (Speedo) under the slogan: 'This is the country of the kimono'. This commission resulted in him developing his own theory about colours that particularly suited Japanese skin colour; indeed his obsession with getting it just right led to him assessing and fine tuning the
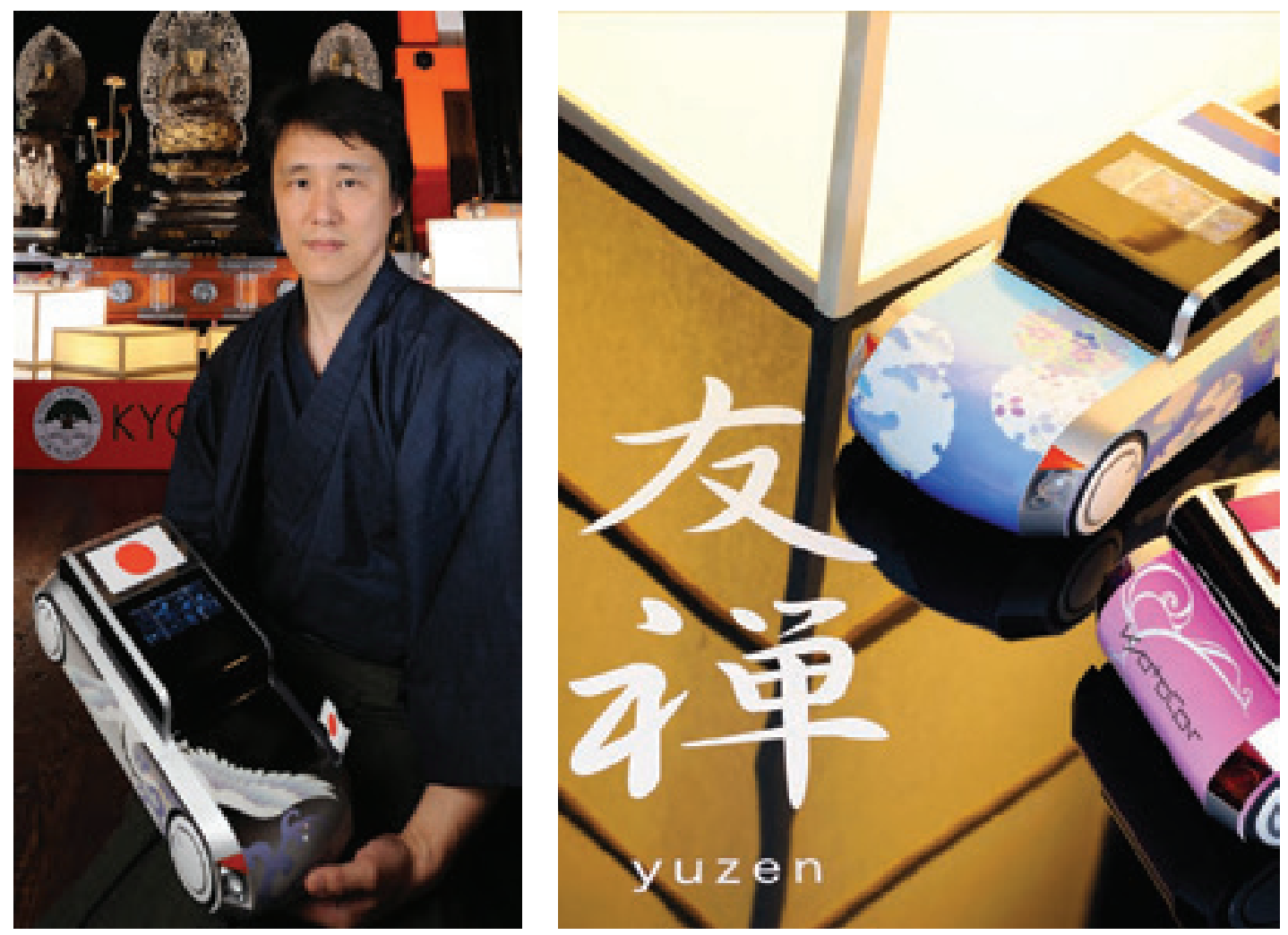

Figure 7.5 Yunosuke Kawabe (left) pictured with one of his Yuzen cars he designed with Takahashi for the G8 Foreign Ministers' Meeting in 2008 (right). (c) Yunosuke Kawabe 

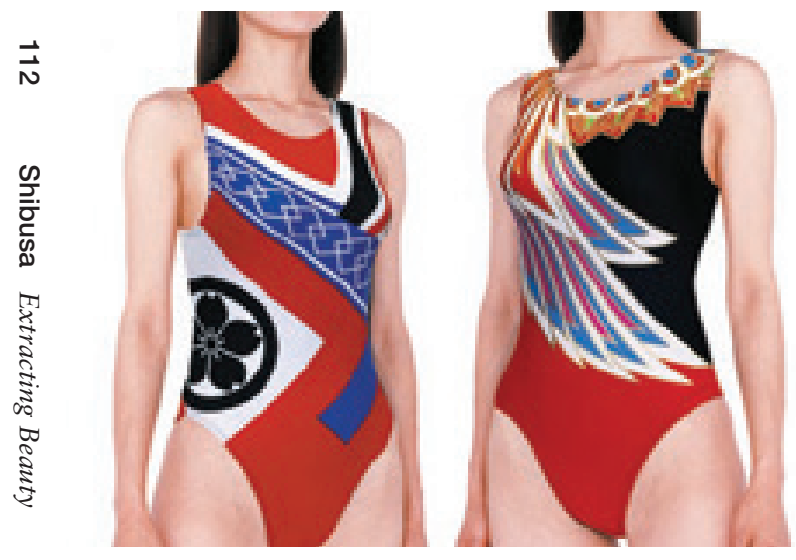

Figure 7.6 Kawabe's successful 2004 Olympic swimsuit design. (c) Yunosuke Kawabe

'colour performance' of the suits against the team's skin under the specific lighting system of the building in Athens where the swimmers were competing.

This fastidious attention to detail harks back to the imperative to protect performance discussed in Chapter 2. Colour and design are unique to individual yuzen workshops - the style often 'absorbed' from one generation to the other. Kawabe's colour palettes, combinations and motifs are 'signatures', in just the same way as those in a painter's portfolio. This is what Professor Murayama describes as 'implicit knowledge': knowledge passed down through the generations. In Yunosuke Kawabe's case he has transferred this knowledge from dye pot and brush to computer brush and palette. Those with a discerning eye of yuzen techniques and styles may very well identify a contemporary work of his and see the influence of his father, Zenji.

Significantly, by developing his inherited yuzen style, Yunosuke Kawabe has successfully broadcast its potential beyond that which might be realised by, say, a few kimono commissions. His Olympic kabuki swimsuit design had a potential viewing audience of 3.9 billion people worldwide the number of people reported to have watched the Athens Olympics in 2004. ${ }^{12}$ His designs represented the Japanese nation, its athletes and Japanese yuzen innovation to a huge potential market - what Murayama describes as 'novel innovations and of going global'. ${ }^{13}$

\section{Taro Matsumara: Bon Kyoto}

Recycling and re-forming the kimono is at the heart of Taro Matsumara's design retail outlet, Bon Kyoto, near Kitashirakawa-Bettocho. ${ }^{14}$ Antique kimonos that are no longer in good enough condition to sell on to be worn are given a new lease of life as jewellery and hair pieces, purses, bags, accessories, 'cute' toys, dolls, and even teddy bears made out of white silk wedding kimonos. While Kyoto has many gift and souvenir shops selling all kinds of products to Japanese visitors and overseas tourists, it is not until you visit Matsumara's store that you are hit by a startling difference the quality of material, design and hand-made construction. Every item is made from antique kimonos of incredible quality.

Matsumara, however, is not doing anything new. Kimono fabric no longer fit enough to wear had, until a few decades ago, been artfully pared down and made fit for another purpose - an obi (sash) perhaps, or child's clothes, or a newly-fashioned accessory. This was the practical solution to maximise the use of the kimono fabric. However, it seems that in recent decades many people have lost the art of recycling and refashioning using craft skills. This is a crucial gap in the market that Matsumara is filling.

The kimono is an expensive, beautiful and unique item. It comes as no surprise that discarding it, or giving it away, is therefore the very last option. The most treasured family kimonos are often well preserved and passed down through the generations. Unfortunately, not all kimonos survive so well. They may have been worn regularly until, literally, they are worn out, stained or have torn sections in the fabric. Perhaps, too, the younger generation no longer has the inclination to sew or refashion fabrics and materials, favouring instead Western fashion and off-the peg solutions.

In a web blog entitled 'Kimonos: are they dying out?' changes in Japanese consumer trends are discussed. One entry states:

Kimonos have long been admired by the West for their luxurious fabric and exquisite designs. But the traditional 
kimono-making industry in Japan is in peril. A lot of this is down to a decline in popularity. Previously the whole of Japan wore kimonos but this is no longer the case; now it's mostly worn for special occasions. [It] is feared that within the next 10 years the art of traditional kimono making will have died out. The industry is
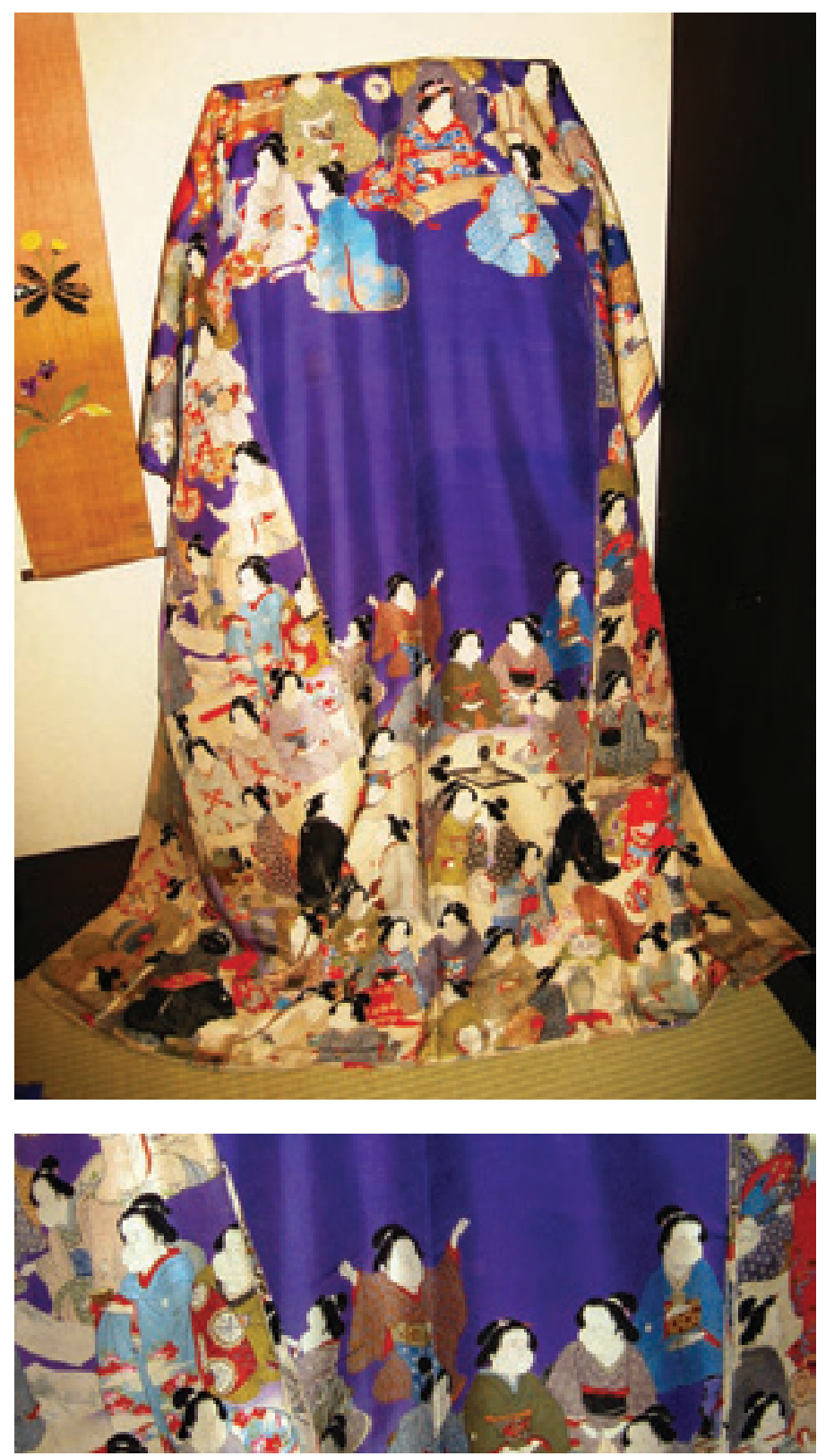

Figure 7.7 One of Matsumara's 'perfect finds': this antique kimono is of the very finest quality. The many kimono-clad characters in the design have their own individual kata-yuzen and hand-painted kimono designs. (C) Taro Matsumara having trouble passing on the skills needed to the next generation. There are very many stages involved in kimono creation and a whole host of different craftspeople are needed and they all possess different areas of expertise. It can take $10+$ years to develop the expertise needed for a single stage. Many of the last remaining kimono artisans are now elderly and it is feared that the kimono industry will die with them. ${ }^{15}$

Another entry comments that:

This is all very disappointing especially as the Japanese economy is thriving. Sadly the new generation are more likely to purchase the latest Louis Vuitton or Chanel bag than a hand-crafted lovingly made traditional kimono. This lull in demand is forcing even some of the premier kimono artisans to use lower-quality foreign silk rather than the much more expensive but superior-quality Japanese silk. Now it's almost impossible to buy $100 \%$ Japanese kimonos. ${ }^{16}$

The change is a cultural and demographic one: fewer Japanese are marrying and many brides opt not for the traditional uchikake and kakeshita (or furisode) arrangement - exotic wedding kimonos worn in layers - but prefer instead Western-style dresses. The birth rate in Japan is also falling, which has reduced sales in children's kimonos used for celebrations.

Matsumara's passion and knowledge of kimonos is at the heart of his business. He combines his personal interest in kimonos with commerce. He is drawn to antique kimonos not only for their obvious beauty, but also for the social history that individual pieces reveal through their motifs, patterns, colours, techniques and materials. Matsumara's educated eye for a perfect kimono, therefore, has spawned an exceptional collection and is a valuable contribution to the preservation of Kyoto's social and artistic history (see Figure 7.7). Kimonos that do not pass the test of being of 'collectable' standard are earmarked for use as material for his new designs.

Matusmara employs four designers, who each bring their own individual flair to reconfiguring, by hand, new innovations. 
The result is a shop of wonders - a wide range of products that show off the qualities of each kimono remnant in innovative and pleasing ways. These items, constructed from fragments, reveal the 'devil in the detail' within the kimonos' rich and extravagant designs. Small amounts of fabric are transformed into objects singing with colour and pattern - some as gifts or toys, others becoming utilitarian again as obis, shawls, stoles or bags.

A light-hearted yet illuminating example of how a kimono may evidence social history including short-lived fads and fashions - is revealed in this excerpt from a newsletter of kimono sellers. Owner Ichiro Wada describes one of their most recent kimono 'finds' - a meisen ${ }^{17}$ kimono from the mid-Showa period (1926-89) depicting the motif of a spitz dog:

The dog is Japanese spitz, which was the most popular dog in Showa in the 1920s and 1930s. When I was a boy, many neighbors had spitz! It is said that more than $40 \%$ of registered dogs ... were spitz. Japanese original dogs were Shiba Inu and similar, so Japanese at that time were fascinated by [the] white long hairs of [the] spitz. However, the boom quickly passed, and recently we seldom see the spitz. Regrettably, spitz became [known as] the 'dog who bark often in vain' and popularity transfer[red] to the Maltese and Pomeranian. This meisen kimono must have been made when the spitz boom was at the peak. And with this piece, we can know how [the] spitz was once loved. ${ }^{18}$

\section{Makato Mori: kimono designer}

Makoto Mori is a young kimono designer. ${ }^{19}$ In Chapter 8 he outlines the division of labour (involving many artisans) within traditional kimono making, and compares this to contemporary approaches of working as an artisan (individual) in the industry. Makoto Mori is the son of a traditional kimono designer. However, with the demise of many skilled artisans and the fall in demand for kimonos, developing a successful practice within the industry has not been straightforward for him - or other contemporary designers. As with Kawabe's practice, there is a fusion between old and new in Mori's work: absorbing traditional techniques and rendering them in contemporary contexts (see Figure 7.8) using computer technology, combined with innovative approaches within the marketplace.

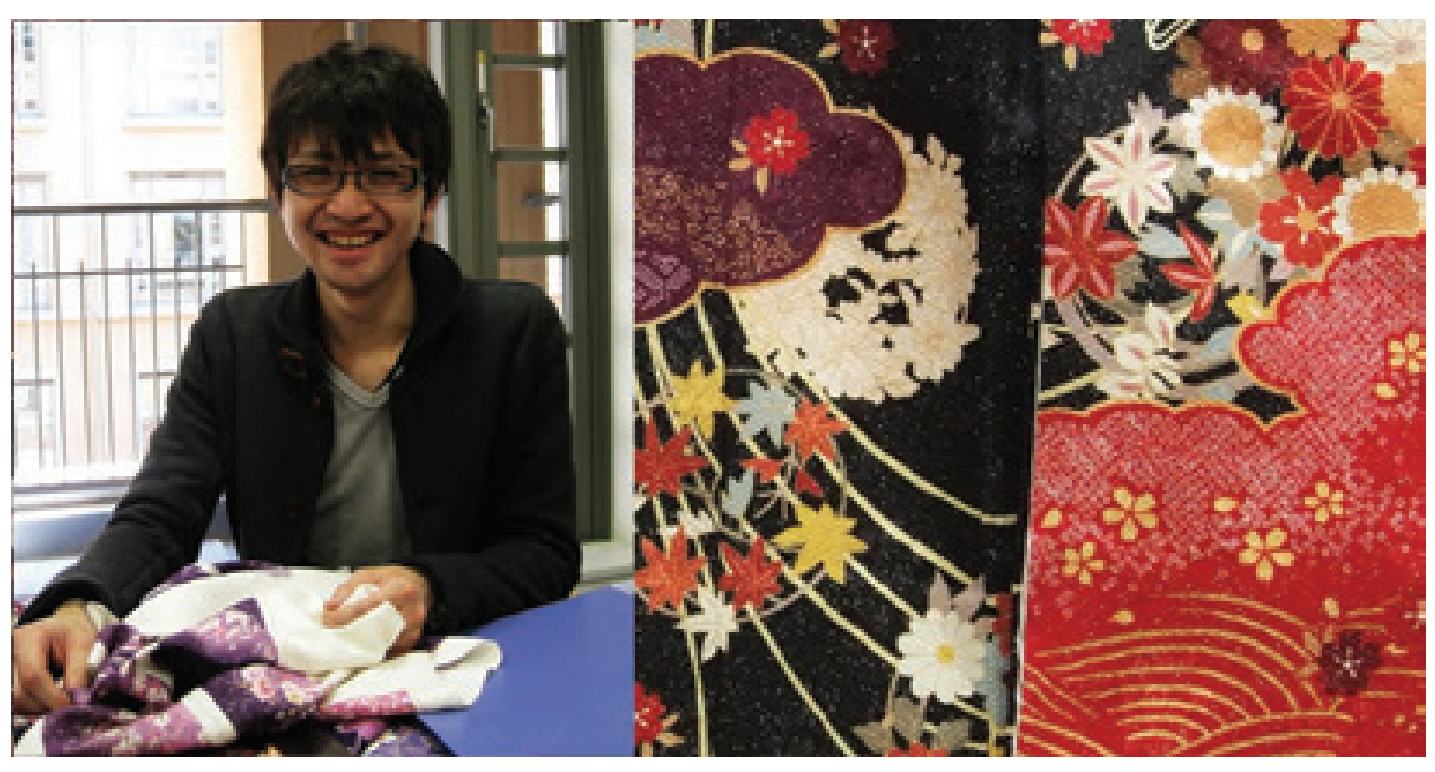

Figure 7.8 Makoto Mori with one of his designs (inset shows the detail of the design). (C) Makoto Mori 

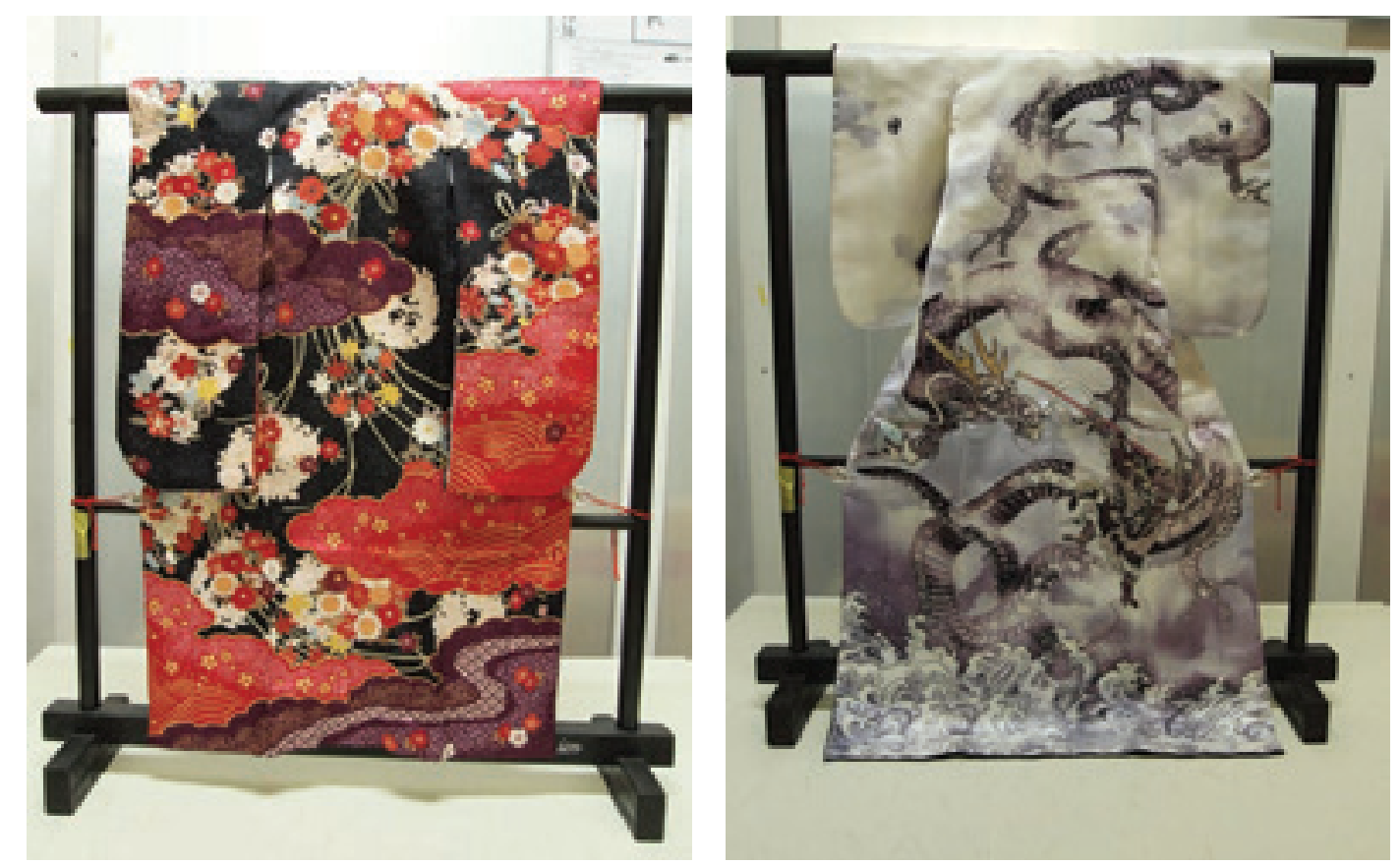

$\vec{v}$
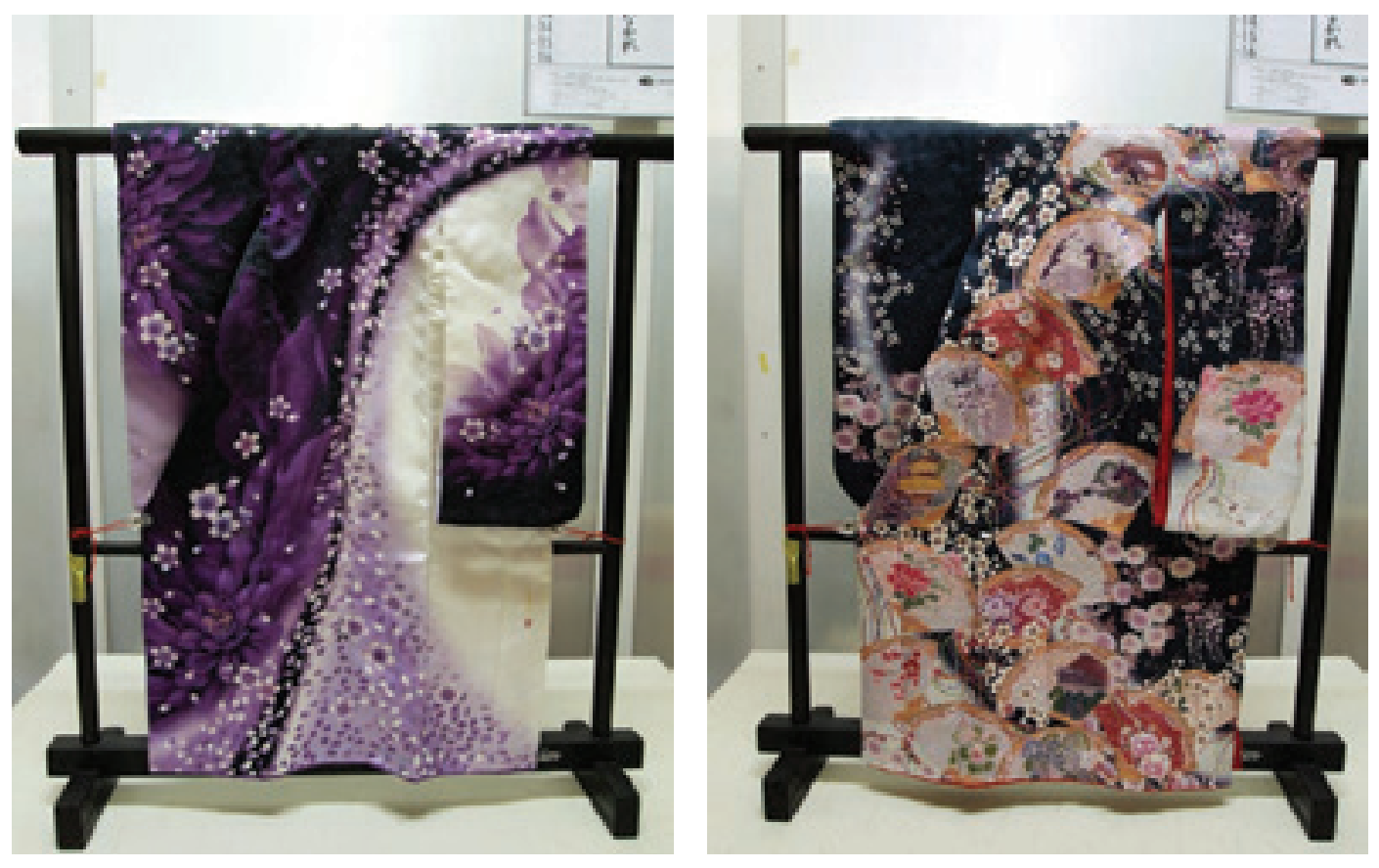

Figure 7.9 Examples of Mori's doll-size kimonos. (c) Makoto Mori 


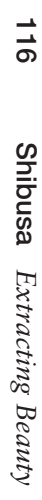

Makato Mori has had to use lateral thinking in his design, production and marketing strategies. For example, he capitalises on the popular tradition of the hina matsuri doll ceremony to promote his kimonos. ${ }^{20}$ By creating doll-size kimonos, Mori catches the eye of potential clients who may wish to have the design (or similar) emulated as kimonos that they can wear (see Figure 7.9). Not only does this promote his designs to a wider audience, but by scaling down his kimono he can also economise on material and labour costs.

\section{Notes}

1 D. Demetriou, 'Kimono making in Japan is a dying art', The Telegraph, 23 October 2010.

Ibid.

Ibid.

A. Faiola, 'Twilight for the kimono', Washington Post Foreign Service, 13 December 2006.

Ibid.

Y. Murayama, From Heritage Industries to Cultural Businesses: Innovative Globalization of Kyoto's Heritage Industries - The Kakushin Juku, Doshisha Business School, 2006_2008 (Kyoto: Doshisha University, 2008).

It is very hard to find a parallel in Western culture that would equate to this predicament.

www.jss-kyoto.jp/index.html www.ichiroya.com Murayama, From Heritage Industries. Japanese theatre with a tradition of elaborate and dramatic costumes. J. Swaine, 'Beijing Olympics: opening ceremony watched by 15 per cent of world's population', The Telegraph, 12 August 2008.

Murayama, From Heritage Industries. www.bon-kyoto.co.jp/en/index.html http://fuyume.net/2011/01/kimonosarethey-dying-out.html

Ibid.

Meisen is woven fabric with blurred and colourful patterns, which is produced by using pre-dyed threads. The technique is related to earlier methods of kasuri (ikat), in which threads are resisted before dyeing and weaving, and e-gasuri ('picture-ikat') where motifs and patterns are 'drawn' on to groups of threads using resist paste through a stencil. Meisen was particularly popular following the First World War up to the mid-1950s.

I. Wada, Ichiroya's Newsletter 400, 5 June 2011.

www.tocomarimo.com

Hina matsuri is a doll festival organised annually to pray for the growth and happiness of young girls. A hundred dolls are arranged in five or seven-tiered stands covered in red carpet. The dolls are called bina-ningyo. 